\title{
Proximate causes of natal dispersal in female yellow-bellied marmots, Marmota flaviventris
}

\author{
Kenneth B. Armitage, ${ }^{1}$ Dirk H. Van Vuren, ${ }^{2}$ Arpat Ozgul, ${ }^{3}$ and Madan K. Oli ${ }^{4,5}$ \\ ${ }^{1}$ Department of Ecology and Evolutionary Biology, University of Kansas, Lawrence, Kansas 66045 USA \\ ${ }^{2}$ Department of Wildlife, Fish, and Conservation Biology, University of California, Davis, California 95616 USA \\ ${ }^{3}$ Division of Biology, Imperial College London, Silwood Park, Ascot, Berks SL5 7 P Y United Kingdom \\ ${ }^{4}$ Department of Wildlife Ecology and Conservation, University of Florida, 110 Newins-Ziegler Hall, Gainesville, Florida 32611 USA
}

\begin{abstract}
We investigated factors influencing natal dispersal in 231 female yearling yellow-bellied marmots (Marmota flaviventris) using comprehensive analysis of 10 years (1983-1993) of radiotelemetry and 37 years (1963-1999) of capture-mark-recapture data. Only individuals whose dispersal status was verified, primarily by radiotelemetry, were considered. Univariate analyses revealed that six of the 24 variables we studied significantly influenced dispersal: dispersal was less likely when the mother was present, amicable behavior with the mother and play behavior were more frequent, and spatial overlap was greater with the mother, with matriline females, and with other yearling females. Using both univariate and multivariate analyses, we tested several hypotheses proposed as proximate causes of dispersal. We rejected inbreeding avoidance, population density, body size, social intolerance, and kin competition as factors influencing dispersal. Instead, our results indicate that kin cooperation, expressed via cohesive behaviors and with a focus on the mother, influenced dispersal by promoting philopatry. Kin cooperation may be an underappreciated factor influencing dispersal in both social and nonsocial species.
\end{abstract}

Key words: density dependence; dispersal; inbreeding avoidance; kinship; Marmota flaviventris; resource competition; social cohesion; space-use overlap; yellow-bellied marmot.

\section{INTRODUCTION}

Natal dispersal, the permanent movement of an animal away from its birth site to where it actually or potentially breeds, is common among mammals and has important implications for demography, genetic structure, distribution, and social evolution (Greenwood 1980, Waser and Jones 1983, Bowler and Benton 2005, Ronce 2007). Early work suggested that dispersal tendency had a genetic basis (Howard 1960, Gaines and McClenaghan 1980), but more recent work indicates that dispersal may be a life history strategy that is plastic, expressed conditionally in response to environmental cues (Waser and Jones 1989, Bowler and Benton 2005, Ronce 2007). The decision to emigrate or not has fitness consequences (Waser and Jones 1983, Bowler and Benton 2005); hence, natural selection might favor the ability of the potential emigrant to recognize appropriate cues (Grant 1978, Waser and Jones 1989).

The three general explanations for the dispersal decision in mammals are inbreeding avoidance, competition for mates, and competition for environmental resources (Greenwood 1980), and more than one factor may motivate dispersal in a given individual (Dobson

Manuscript received 16 January 2010; revised 28 April 2010; accepted 4 May 2010; final version received 9 June 2010. Corresponding Editor: T. J. Valone.

${ }^{5}$ Corresponding author. E-mail: olim@ufl.edu and Jones 1985). Because of the potential fitness cost of inbreeding depression, juveniles may emigrate to avoid mating with close relatives; hence, a cue for emigration might be potential mating partners limited to the opposite-sex parent or siblings (Wolff 1992, Pusey and Wolf 1996). Adults may compete for mates or mating opportunities, and this competition may be especially intense among males in the polygynous mating system common in mammals (Dobson 1982). Thus, the presence of a same-sex adult in the natal home range may stimulate dispersal.

Dispersers may emigrate because of competition for resources besides mates, such as food, space, and nest sites (Murray 1967, Grant 1978, Holekamp 1986). Population density of conspecifics may be an important cue influencing the dispersal decision, but high population density may have either of two effects; the juvenile might emigrate to escape competition in the natal area, or remain philopatric because high population density beyond the natal area indicates poor prospects for successful dispersal (Matthysen 2005). Competition with relatives might influence the dispersal decision because of the implications for inclusive fitness (Lambin et al. 2001, Bowler and Benton 2005). The effect of competition, for either mates or resources, may be mediated through dominance and aggression (Hanski et al. 1991, Wolff 1993, Matthysen 2005), with low-ranking subordinates induced behaviorally to disperse (Christian 1970, Gaines and McClenaghan 1980). Larger individuals may 
be competitively superior; hence, smaller individuals would be more likely to emigrate (Hanski et al. 1991, Bowler and Benton 2005). Body size, however, might have the opposite effect: Larger individuals may be more likely to emigrate because they have the fat reserves to meet the energy demands of dispersal (Nunes et al. 1998). Finally, Bekoff (1977) proposed that dispersal results not from presence of agonistic interactions at the time of emigration but from the absence of cohesive interactions such as social play before emigration.

We studied dispersal in the yellow-bellied marmot (Marmota flaviventris; see Plate 1), an ideal species for studying factors influencing dispersal because some females disperse, primarily as yearlings, whereas others remain philopatric (Van Vuren and Armitage 1994a). We analyzed the effects of 24 possible cues on natal dispersal of female yellow-bellied marmots for 37 years using radiotelemetry (1983-1993) and capture-markrecapture and visual observation (1963-1999). We tested five hypotheses about the causes of dispersal: dispersal occurs to avoid inbreeding, dispersal results from high density in the natal area, dispersal is related to the body size of the disperser, dispersal is caused by social intolerance, and dispersal functions to reduce kin competition. We consider only females because all males disperse, primarily as yearlings (Armitage 1974, 1991).

\section{Methods}

The yellow-bellied marmot is a diurnal, grounddwelling squirrel that occupies discrete habitat patches characterized by rocky outcrops or talus with adjoining meadows in a mosaic of aspen and spruce woodlands in the upper East River Valley near the Rocky Mountain Biological Laboratory, Colorado, USA (Svendsen 1974) (see Plate 1). The habitat patches provide two essential resources: burrow sites and foraging areas (Armitage 1991, 2003a). Smaller sites were designated satellites and typically are occupied by a single adult female, her young and yearling offspring, and often an adult male (Svendsen 1974, Armitage 1991). Larger sites were designated colonies that comprise one or more matrilines, each consisting of one to five adult females, young, and yearlings. In colonies, typically one, but as many as three adult males, maintain territories that include one or more matrilines but exclude other adult males. Territorial males that die or disappear are typically replaced quickly by a male born outside the site (Armitage 1974, Armitage and Schwartz 2000, Armitage 2004).

At each of the study sites each year, marmots were trapped and weighed, and age, sex, and reproductive condition were recorded. Each marmot was permanently identified with numbered ear tags. At four of the six colony sites we studied, each marmot was marked with fur dye for identification during behavioral observations. Marmots were observed primarily between 06:30 and 10:00 hours, and 16:30 and 19:00 hours, when marmots are most active. Social interactions were observed by scan sampling and recorded as amicable, agonistic, or play (Armitage 2003a). At regular intervals the spatial location of each marmot was recorded (Frase and Armitage 1984). Observations totaled $5700 \mathrm{~h}$ or $\sim 140 \mathrm{~h}$ each year. Because marmots hibernate, they were observed during the peak months of activity from June through August. Because of logistic constraints, behavioral and space-use data were not obtained at two colony sites and at the five satellite sites we studied. All other variables were measured for all sites.

Dispersal in yellow-bellied marmots typically occurs at one year of age (Van Vuren 1990). Thus, we restricted our analysis to yearlings, and used only those female yearlings whose residency or dispersal status was confirmed. From 1983 through 1993 we used radiotelemetry to determine residency or dispersal status. During this period all female yearlings were fitted with radio-transmitters shortly after emergence from hibernation, and were radio-located regularly throughout the summer until they hibernated. Dispersers were those animals that made a permanent, one-way movement away from their natal home range before entering hibernation, which almost always meant emigration from the colony or satellite site where they were born. Philopatric animals were those that hibernated in their natal home range. In all other years we used a combination of trapping and observation to determine dispersal status. Philopatry was indicated if a yearling female was trapped or observed as a two-year-old at her natal site. Dispersal was indicated when a female yearling vanished from her natal site and was subsequently trapped or observed at another site, either as a yearling or a two-year-old. Instances of dispersal verification by trapping and observation were few; usually the yearling disappeared and we could not distinguish between death and dispersal as the cause. Thus, radiotelemetry confirmed the dispersal status of most yearling females.

We considered four categorical variables that can potentially influence dispersal (Appendix A). The presence or absence of the yearling's father was used to test whether dispersal was related to inbreeding avoidance. Genetic and other evidence indicates the territorial male is the only mating opportunity for females in his territory (Armitage 2004). To test whether body mass influenced the probability of dispersal, we used body mass recorded during June; most females disperse during June and July (Van Vuren 1990). We conducted regression analyses of body mass of all female yearlings against time. Because emergence times are usually later at sites at the upper end of the valley than at the lower end of the valley, regressions were calculated for each area. For each female, we recorded whether its body mass in June was above or below the regression line for its location. The other two categorical variables were mother's presence or absence, and, if the mother was present, her reproductive status (Appendix A). The mother may treat her daughter as a potential 
competitor, especially if the mother is reproductive (Wiggett and Boag 1992a, Gundersen and Andreassen 1998, Ronce 2007). However, in a matrilineal species, the presence of the mother may have the opposite effect and promote philopatry (Armitage 1984).

The continuous variables were organized into three groups that quantified population density, social behavior, and kinship (Appendix B). Density variables included the relative density of adult females at a site, relative density of adult females in the matriline, and number of female yearlings in the matriline. Because the mean number of resident females across years varied from 1.43 to 6.35 among sites, density was expressed as relative density by dividing the number of adult females in a given year by the long-term average for that site when occupied. Similarly, matriline size, which varied from 1.0 to 1.9 among sites, was divided by mean matriline size at that site across years to provide an index of relative matriline density. The number of yearling females in the matriline reflected the potential competition for residency.

All behavioral data consisted of rates, which were calculated as the number of behaviors per animal per hour. Because the grappling of a female by an adult male results in agonistic behavior in that the female breaks away and flees (Armitage 1974), repeated grappling or mounting by the male could increase avoidance of the male that leads to dispersal. Increased rates of play could promote social cohesion that leads to a decreased probability of dispersal (Bekoff 1977). Agonistic behavior is expected to increase the probability of dispersal and amicable behavior to decrease the probability of dispersal. Location records were used to calculate the degree to which individuals shared space (space-use overlap; Armitage 1989), which is a measure of which individuals share the critical resources of burrow sites and foraging areas. Close kin, such as yearlings and their mothers (relatedness $=0.5$ ), had higher values of spaceuse overlap than more distant kin or unrelated females (Armitage 1984). Therefore, we predicted that high values of space-use overlap with close kin reflected social tolerance and would reduce the probability of dispersal.

Kinship has been implicated as a potentially important factor influencing dispersal (Bowler and Benton 2005). Kin competition between parents and offspring is expected to increase the probability of dispersal whereas kin cooperation could increase philopatry (Lambin et al. 2001). Because virtually every marmot in the study sites was trapped each year, we could estimate the relatedness among individuals based on the genealogy of each female (Oli and Armitage 2008). From the coefficients of relatedness, we calculated the average relatedness of each yearling with all females in the matriline and with other female yearlings, who could be sisters, half-sisters, cousins, etc.

We used logistic regression analyses (generalized linear models with logit-link function; Agresti 2002) to model the probability of dispersal as a function of independent variables. We first tested for the effect of each independent variable by modeling dispersal probability as a function of one variable at a time. When a hypothesis involved only one variable, this provided an adequate test of that hypothesis. For example, the inbreeding avoidance hypothesis was tested by evaluating the effect of the presence of father on dispersal probability. When a hypothesis involved two or more variables, however, we conducted a stepwise variable selection procedure with $\alpha=0.15$ for a variable to enter or to leave a model, starting with variables that significantly influenced dispersal probability in single variable analyses at $\alpha=0.15$. We then fitted the final model including only those variables selected by the stepwise variable selection procedure. Simultaneous consideration of all factors was not feasible due to sample size limitations. All statistical analyses were conducted using LOGISTIC procedure in SAS version 9.2 (SAS Institute 2009), except that GLIMMIX procedure (SAS Institute 2009) was used to estimate least squares means for categorical variables.

\section{Results}

\section{Univariate analyses}

We assessed factors associated with the dispersal decision for 231 female yearling marmots. The univariate analyses revealed that six of the 24 variables we measured significantly influenced the probability of dispersal ( $P<0.05$; Table 1). Among the categorical variables, only the presence or absence of the mother significantly influenced dispersal; yearling females were more likely to be philopatric if their mother was present and were more likely to disperse if their mother was absent (Table 1, Fig. 1). Body mass, presence or absence of the father, and reproductive status of the mother had no significant influence on dispersal (Table 1, Fig. 1).

Among the continuous variables, none of those related to population density significantly influenced dispersal (Table 1, Fig. 2). For the social variables, play had a significant negative influence on dispersal and explained over one-fourth of the variation (as quantified by generalized max-rescaled $R^{2}$; Table 1 ). By contrast, grappling by adult males did not influence dispersal. The effect of amicable behavior varied markedly among the three variables (Table 1, Fig. 3). Amicable behavior with the mother had a significant negative influence on dispersal, and explained $\sim 28 \%$ of the variation. Because the mother was a member of a matriline, we expected that amicable behavior with matriline females would be important. However, amicable behavior with other females, either matriline or non-matriline, did not influence dispersal (Table 1, Fig. 3). None of the agonistic behaviors or measures of the proportion amicable significantly influenced dispersal. Space-use overlap with the mother, with matriline females, and with yearling females all had a significant negative influence on dispersal and explained a considerable amount of the variation, but space-use overlap with 
TABLE 1. Results of the univariate analyses of the variables used in the analysis of dispersal of yellow-bellied marmots, Marmota flaviventris in the upper East River Valley near the Rocky Mountain Biological Laboratory, Colorado, USA.

\begin{tabular}{|c|c|c|c|c|}
\hline \multirow[b]{2}{*}{ Variables } & \multicolumn{3}{|c|}{ Slope parameter, $\beta$} & \multirow[b]{2}{*}{$R^{2}$} \\
\hline & Estimate & Standard error & $P$ & \\
\hline Inbreeding: father absent & 0.079 & 0.142 & 0.577 & 0.0019 \\
\hline Yearling mass: above the mean & 0.068 & 0.151 & 0.653 & 0.0013 \\
\hline \multicolumn{5}{|l|}{ Competition with mother } \\
\hline Mother absent & 0.340 & 0.152 & $0.026^{*}$ & 0.0295 \\
\hline Mother nonreproductive & -0.265 & 0.192 & 0.168 & 0.0171 \\
\hline \multicolumn{5}{|l|}{ Density variables } \\
\hline Adult female density & 0.041 & 0.176 & 0.816 & 0.0003 \\
\hline Matriline density & -0.159 & 0.210 & 0.450 & 0.0035 \\
\hline Number of female yearlings & 0.023 & 0.080 & 0.777 & 0.0005 \\
\hline \multicolumn{5}{|l|}{ Social variables } \\
\hline Adult male grapples & -11.522 & 9.391 & 0.220 & 0.023 \\
\hline Play & -35.252 & 11.959 & $0.003^{*}$ & 0.266 \\
\hline \multicolumn{5}{|l|}{ Amicable behavior } \\
\hline Mother & -56.046 & 27.214 & $0.039 *$ & 0.285 \\
\hline Matriline females & -17.514 & 12.788 & 0.171 & 0.063 \\
\hline Non-matriline females & 92.665 & 86.042 & 0.282 & 0.03 \\
\hline \multicolumn{5}{|l|}{ Agonistic behavior } \\
\hline Mother & -39.648 & 32.737 & 0.226 & 0.073 \\
\hline Matriline females & -6.795 & 8.859 & 0.443 & 0.019 \\
\hline Non-matriline females & -107.7 & 69.718 & 0.1225 & 0.009 \\
\hline \multicolumn{5}{|l|}{ Proportion amicable } \\
\hline Mother & -1.746 & 1.019 & 0.087 & 0.121 \\
\hline Matriline females & -0.654 & 0.847 & 0.440 & 0.020 \\
\hline Non-matriline females & 0.914 & 1.358 & 0.501 & 0.024 \\
\hline \multicolumn{5}{|l|}{ Space-use overlap } \\
\hline With mother & -10.881 & 2.887 & $0.0002^{*}$ & 0.448 \\
\hline With matriline females & -7.928 & 2.810 & $0.005^{*}$ & 0.277 \\
\hline With non-matriline females & -2.434 & 6.734 & 0.718 & 0.003 \\
\hline With yearling females & -4.904 & 1.341 & $0.0003^{*}$ & 0.258 \\
\hline \multicolumn{5}{|l|}{ Kinship (average relatedness) } \\
\hline With matriline females & -2.739 & 1.736 & 0.115 & 0.018 \\
\hline With yearling females & 3.270 & 1.730 & 0.059 & 0.027 \\
\hline
\end{tabular}

Notes: The slope parameter is for logistic regression modeling dispersal probability as a function of the listed variable. The $P$ values test the hypothesis that slope $=0$. An asterisk indicates significance at $P=0.05$. The generalized max-rescaled coefficient of determination $\left(R^{2}\right)$ is also given.

non-matriline females did not (Table 1, Fig. 4). In particular, space-use overlap with the mother explained $45 \%$ of the variation, suggesting that this is a particularly influential variable. The two kinship variables did not significantly influence dispersal, and neither explained much of the variation in the probability of dispersal.

\section{Tests of hypotheses}

Three hypotheses were tested using the univariate analyses. The inbreeding avoidance hypothesis was rejected because the presence of a yearling's father did not significantly affect dispersal probability. The hypothesis that dispersal results from high density in the natal area was rejected because none of the variables related to population density significantly influenced dispersal. The hypothesis that dispersal is related to body size was rejected because body size had no significant effect on dispersal (Table 1).
The hypothesis that dispersal is caused by social intolerance was tested with a multivariate analysis of all 15 of the social and space-use overlap variables. The hypothesis was not supported. The variable selection procedure revealed that none of the variables quantifying agonistic behavior influenced dispersal, and that only space-use overlap with mother had a significant effect on the probability of dispersal; greater overlap promoted philopatry. This result, along with those from the univariate analyses, indicated that cohesive behaviors, rather than agonistic behaviors, were important factors influencing dispersal. The hypothesis that dispersal functions to reduce kin competition was tested with a multivariate analysis of the four variables under competition with the mother and under kinship. The variable selection procedure chose only one variable, mother absent, and the effect on dispersal was positive instead of negative. Hence, the hypothesis was rejected. 

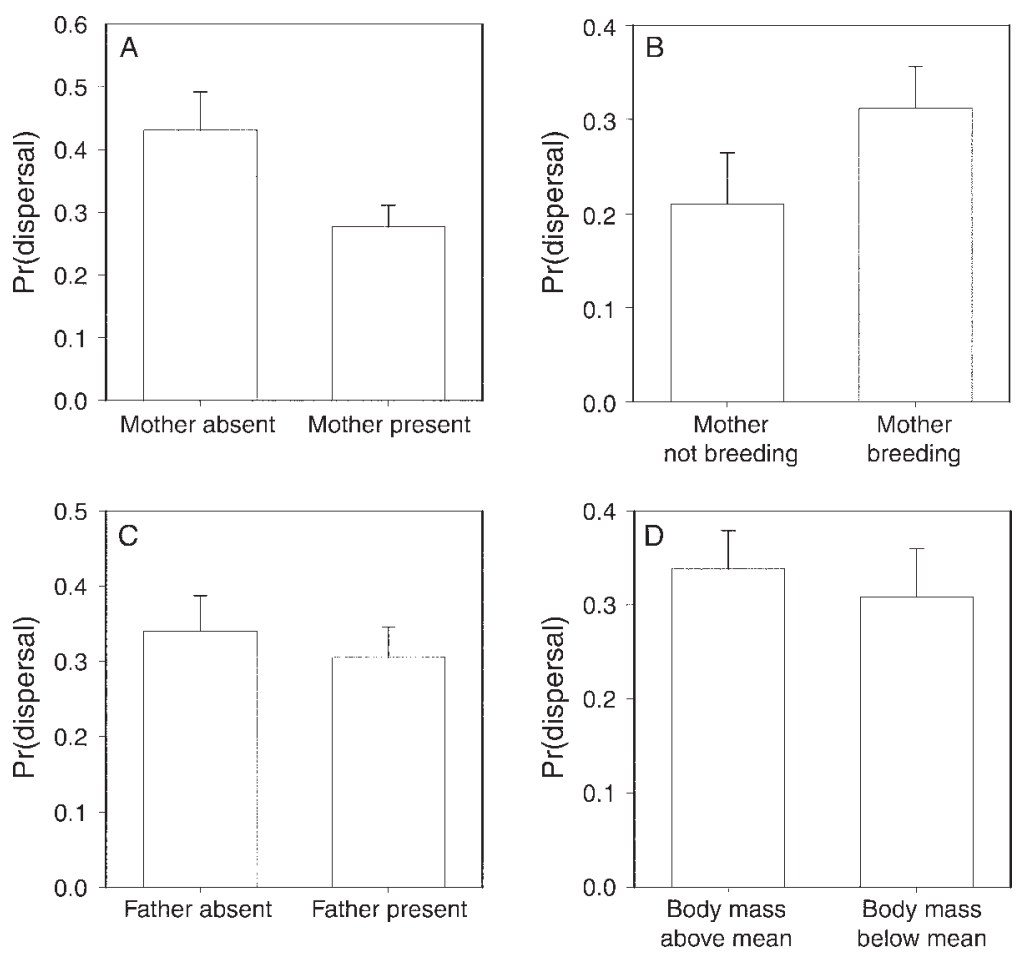

FIG. 1. The mean predicted probability (Pr) of dispersal of yellow-bellied marmots (Marmota flaviventris): (A) when the mother is present or absent; (B) whether or not the mother is breeding (if present); (C) when the father is present or absent; and (D) whether body mass in June is above or below the mean body mass. Values are means + SE.

\section{DiscusSION}

The importance of inbreeding avoidance in explaining sex-biased dispersal has been debated (Moore and Ali 1984, Dobson and Jones 1985, Waser 1985, Holekamp and Sherman 1989, Wolff 1993, Pusey and Wolf 1996), and resolution of the debate has been difficult in part because it is often unclear whether inbreeding avoidance is a cause or a consequence of dispersal (Greenwood 1983). Nonetheless, inbreeding is a potential cost of philopatry, and the presence of an opposite-sex parent should be a cue promoting dispersal (Wolff 1993). The average tenure of an adult male marmot is relatively short, but some males are long lived (Armitage 1991), resulting in a potential for father-daughter matings that occurs at an overall frequency of $10 \%$ (Armitage 2004). Moreover, inbreeding in marmots entails a fitness cost; frequency of reproduction and litter size are unaffected, but survival of resulting offspring is $10 \%$ lower (Armitage 2004). However, we found that inbreeding avoidance had no influence on dispersal of female marmots. Wolff (1992) found a contrasting result for white-footed mice: Dispersal was more likely if an opposite-sex parent was present. Tests of this hypothesis in other species are few and produced mixed results. Dispersal in prairie voles (Microtus ochrogaster) was more likely when an opposite-sex adult relative was present (McGuire et al. 1993). Female gray-sided voles (Clethrionomys rufocanus) were more likely to disperse from male-biased litters (Ims 1990). In Townsend's voles (M. townsendii), inbreeding avoidance influenced the dispersal of males but not females (Lambin 1994). Prairie voles (M. pennsylvanicus) introduced to experimental plots with siblings were more likely to disperse than were those released with nonrelatives (Bollinger et al. 1993).

Density dependence in dispersal has long been of interest in population regulation (Gaines and McClenaghan 1980), and more recently in metapopulation biology (Hanski 2001, Matthysen 2005). Despite this importance, there are few informative studies addressing density dependence in dispersal (Matthysen 2005). The available information suggests that density-dependent dispersal in mammals is fairly common; most studies report a positive effect of population density on dispersal, although dispersal in some species shows a negative or no effect of population density (Matthysen 2005), as we found for yellow-bellied marmots. Hence, the importance of density as a proximate factor influencing dispersal remains equivocal.

Because larger individuals are considered to be competitively superior and are more likely to successfully achieve residency in the natal site, smaller individuals should disperse, an outcome reported for a few species (Hanski et al. 1991, Koopman et al. 2000, Zedrosser et al. 2007). On the other hand, larger individuals are more likely to be successful emigrants and should disperse, an expectation supported by results 

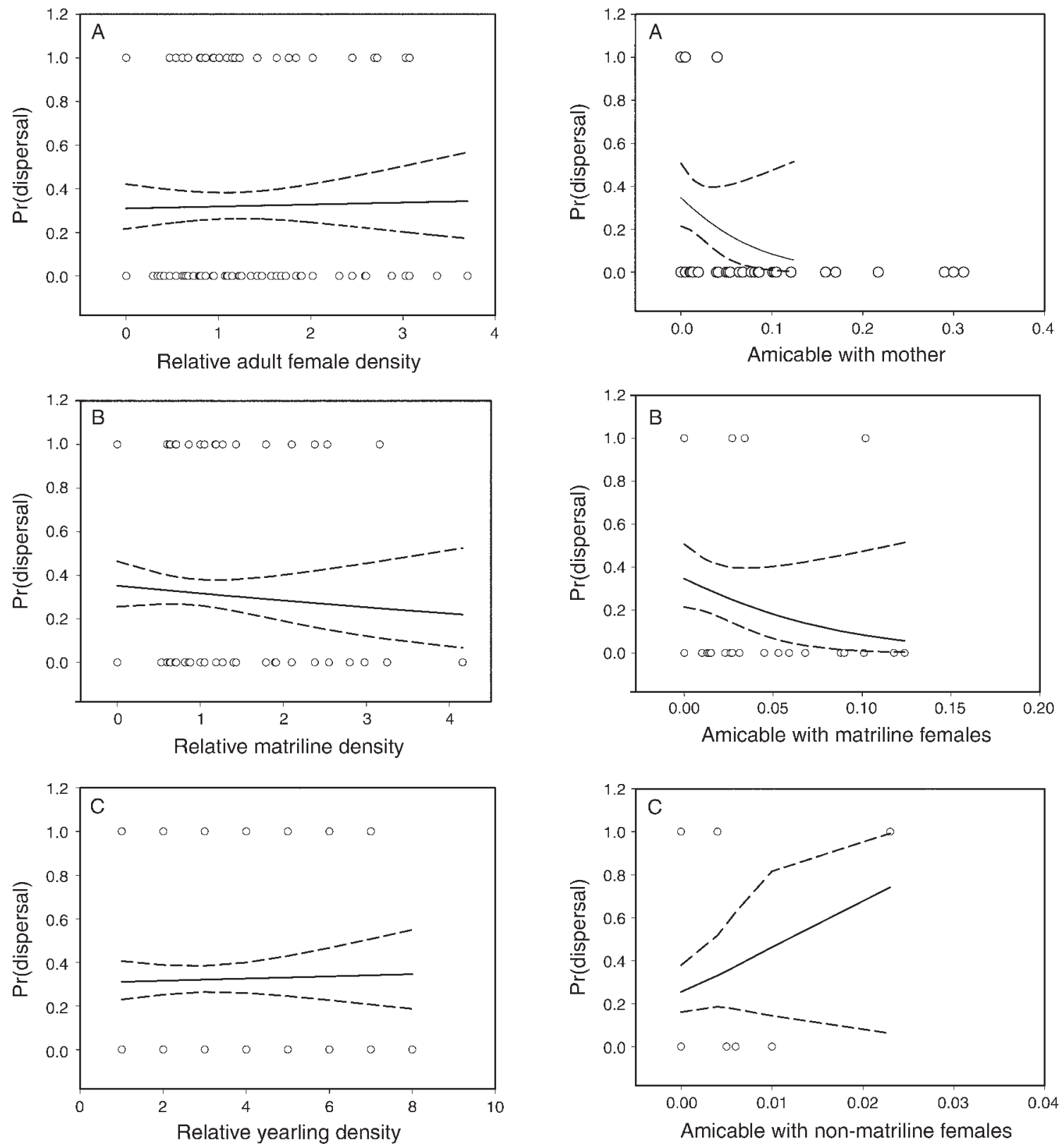

FIG. 2. The relationship between predicted probability of dispersal of yellow-bellied marmots and (A) relative adult female density, (B) relative matriline density, and (C) relative yearling density. The circles represent observed dispersal (1, dispersed; 0, did not disperse), the solid line represents the predicted probability of dispersal, and dashed lines represent the $95 \%$ confidence interval on probability of dispersal. Matriline is defined as those females related by maternal descent that share space.

for Belding's ground squirrels (Spermophilus beldingi; Nunes et al. 1998). However, for most species studied, including yellow-bellied marmots, body mass was unrelated to dispersal (Gregory and Cameron 1988, Wiggett and Boag 1992b, McGuire et al. 1993, Ferreras et al. 2004, Sharpe 2005).

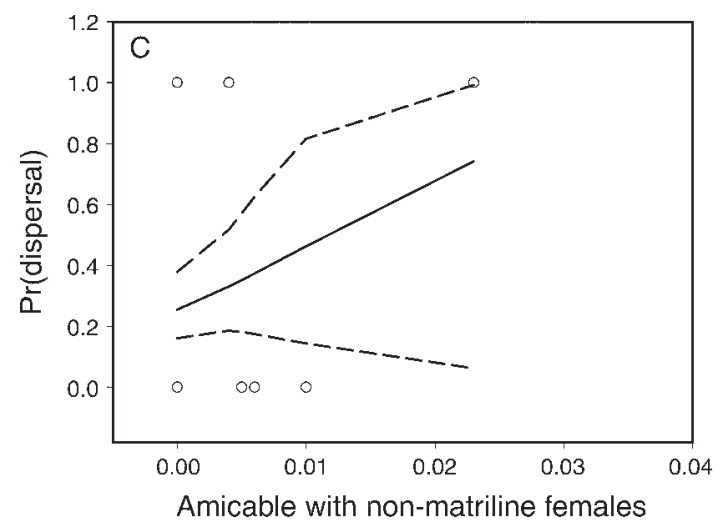

FIG. 3. The relationship between predicted probability of dispersal of yellow-bellied marmots and (A) amicable behavior (behavioral interactions) with the mother, (B) amicable behavior with matriline females, and (C) amicable behavior with nonmatriline females. The circles represent observed dispersal (1, dispersed; 0 , did not disperse), the solid line represents the predicted probability of dispersal, and dashed lines represent the $95 \%$ confidence interval on probability of dispersal.

The rejection of the social intolerance hypothesis implies that social cohesiveness leads to yearling philopatry. Indeed, our results showing the significant effect of play, amicable behavior with the mother, and the three space-use overlap variables on dispersal, along with the absence of a significant effect of agonistic 

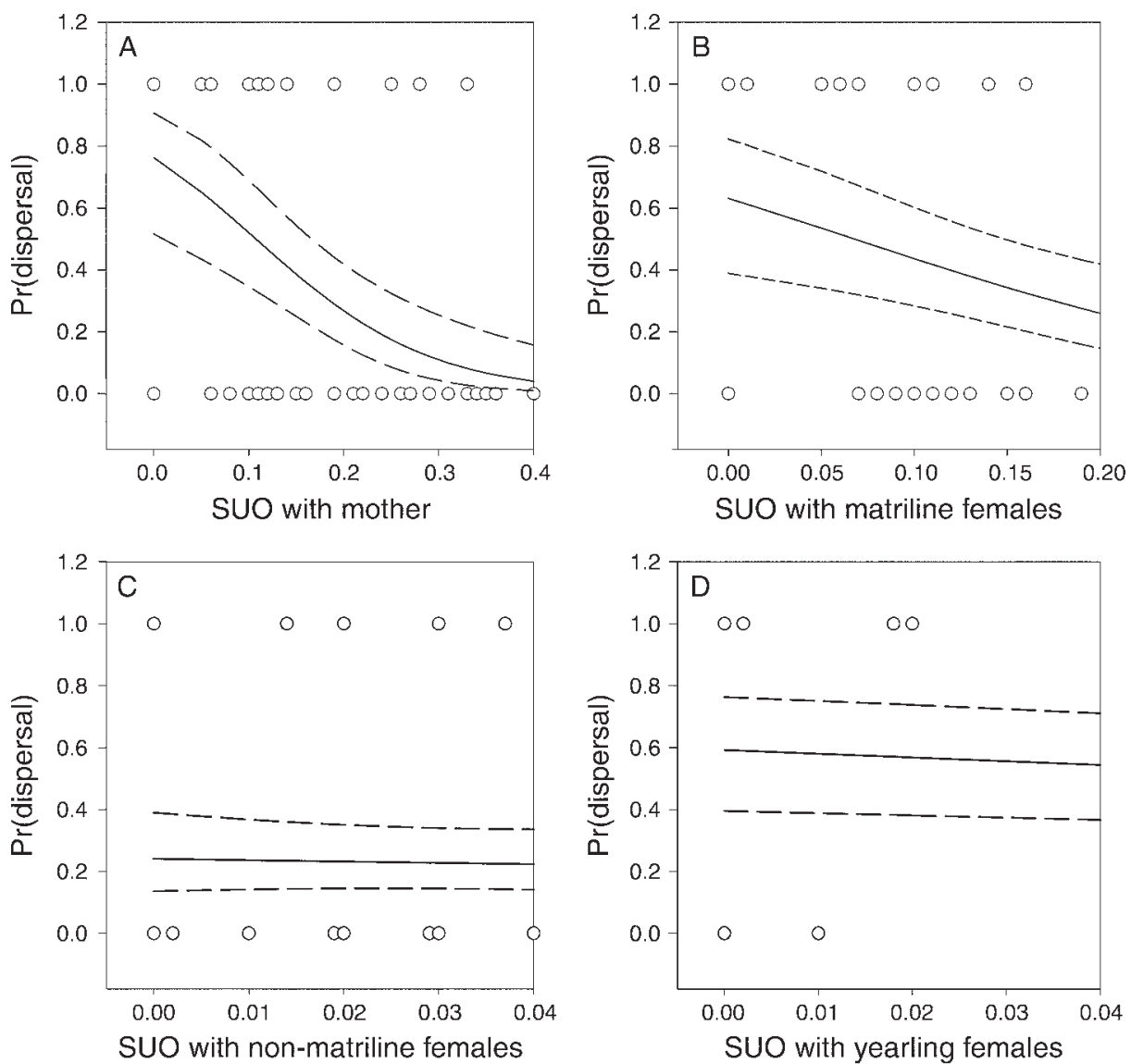

FIG. 4. The relationship between predicted probability of dispersal of yellow-bellied marmots and space-use overlap (SUO) with (A) the mother, (B) matriline females, (C) non-matriline females, and (D) yearling females. The circles represent observed dispersal (1, dispersed; 0 , did not disperse), the solid line represents the predicted probability of dispersal, and dashed lines represent the $95 \%$ confidence interval on probability of dispersal.

behavior (Table 1), all provide support for the social cohesion hypothesis (Bekoff 1977). Similarly, the social cohesion hypothesis was supported in a social network analysis of yellow-bellied marmots in which females that were more socially embedded in their groups were more likely to remain philopatric (Blumstein et al. 2009). However, the social cohesion hypothesis lacks a causal explanation for the cohesive behavior. Our results highlight the role of kin cooperation, involving the mother in particular, but also other members of the matriline, in promoting the social cohesiveness that influences the dispersal decision.

Sociality in yellow-bellied marmots is influenced by both kin competition and kin cooperation (Armitage 1989), with cooperative behaviors emphasizing enhancement of direct fitness via recruitment of daughters (Oli and Armitage 2008). Our results indicate that kin cooperation, instead of kin competition, influences dispersal, with a focus on the mother: whether she is present or not, her amicable behavior toward her daughter, and how much space she shares. Matrilines form and increase in size when an adult female recruits daughters into her home range area (Armitage 1984).
Social behavior is amicable within a matriline, whereas it is agonistic among matrilines (Armitage and Johns 1982, Armitage 2002). As matrilines increase in size, average relatedness decreases and eventually average fitness begins to decrease as well, resulting in division into smaller matrilines that may compete with each other (Armitage 1984, 1987, Armitage and Schwartz 2000). No yearling born in one matriline has ever become resident in the home range of another matriline. Matriline members share space, which represents critical resources; spatial overlap is greatest when the coefficient of relatedness is 0.5 , especially mothers and their daughters, then declines steeply when the coefficient of relatedness is $\leq 0.25$ (Armitage 1996). Space-sharing integrates both close kinship and social tolerance. Because rates of social interactions are strongly affected by individual behavioral phenotypes (Armitage and Van Vuren 2003) and familiarity (Armitage 1977), they do not reflect social integration as well as does spacesharing. In effect, individuals are not integrated into a group unless space is shared.

Given the importance of the mother's presence in promoting philopatry, it was surprising that some 

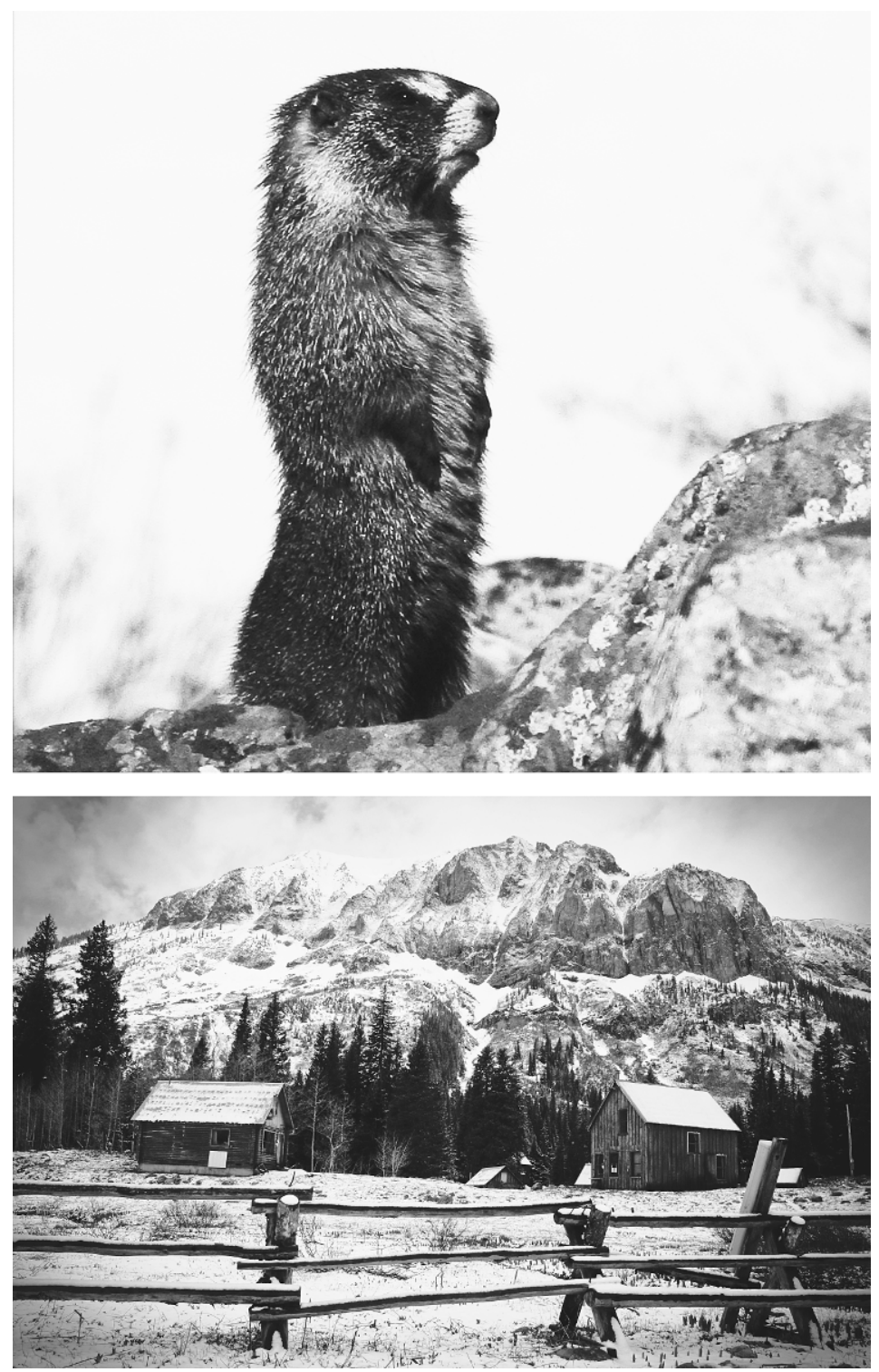

Plate 1. (Top) A yearling yellow-bellied marmot (Marmota flaviventris) and (bottom) the Rocky Mountain Biological Labs, Upper East River Valley, Colorado, USA. Photo credits: A. Ozgul.

female yearlings $(N=36)$ became resident when their mother was absent; we expected that kin competition would promote dispersal without the mother's presence to buffer the yearling from hostility of other females. For most of these cases (81\%), lack of dispersal could be explained by factors that reduced kin competition. For 14 of the 36 yearlings no adult female was present, and another 15 of the 36 yearling females became resident by shifting their activities into an area of the site that was not occupied by adult females in that year.

In yellow-bellied marmots, adult females do not compensate for a loss of reproduction (direct fitness) by foregoing reproduction and assisting relatives to reproduce (indirect fitness); instead, females attempt to maximize direct fitness by producing offspring and by recruiting daughters that themselves reproduce (Armitage 1989, 1991, Oli and Armitage 2008). However, recruitment raises the potential for competition between mother and daughter, which is often expressed through reproductive suppression of the daughter that results in a delay in the age of first reproduction beyond reproductive maturity at age two years (Armitage 2003b).

Although interactions with the mother had a highly significant influence on dispersal, much of the variation in the dispersal decision remained unexplained. For female yearlings, philopatry conveys the benefits of a habitat with the resources for successful survival and reproduction, as well as integration into a social group that provides some degree of protection from predators 
and agonistic conspecifics. A potential cost is reproductive suppression; a one-year delay in the age of first reproduction results in a $20 \%$ loss of fitness (Van Vuren and Armitage 1994a), although some philopatric yearlings succeed in breeding the next year (Armitage 2003b) The alternative strategy is to disperse and attempt to settle elsewhere. One cost of dispersal is a $16 \%$ lower survival compared with residents (Van Vuren and Armitage 1994a), a mortality difference that would not select against dispersal if dispersers can readily immigrate into another site and reproduce at age two. The probability of successful immigration into an occupied colony is low (Armitage 2003c), and most dispersers settled at satellite sites (D. Van Vuren, unpublished data), where reproductive success was similar to that of colonies (Van Vuren and Armitage 1994b). Hence, female yearlings may be using cues in addition to those we measured, such as the likelihood of reproductive suppression in the natal area, and prospects for success elsewhere as revealed through exploratory excursions (Van Vuren 1990).

Explanations for proximate causes of dispersal have focused on competition or inbreeding avoidance (Moore and Ali 1984, Dobson and Jones 1985, Waser 1985, Holekamp and Sherman 1989, Wolff 1993, Pusey and Wolf 1996). Although our analysis reflected correlation rather than causation, our results suggest that for female yellow-bellied marmots, neither of these factors influenced dispersal. Instead, kin cooperation expressed via cohesive behaviors, especially involving the mother, promoted philopatry. We agree with Lambin et al. (2001) that the role of kin cooperation has been underappreciated, in part because of a focus on kin competition in theoretical work, and that kin cooperation may be an important factor influencing dispersal for both social and nonsocial species.

\section{ACKNOWLEDGMENTS}

We thank all the "marmoteers" who contributed to data collection; this work would not have been possible without their dedicated help. Our research was supported by National Science Foundation grants DEB-0224953 (M. K. Oli), G16354, GB-1980, GB-6123, GB-32494, BMS74-21193, DEB78-07327, BSR-8121231, BSR8614690, BSR-9006772 (K. B. Armitage), and DBI-0242960 (to Rocky Mountain Biological Laboratory); the University of Kansas; the Florida Agricultural Experiment Station; the California Agricultural Experiment Station; the American Society of Mammalogists; the American Museum of Natural History; Sigma Xi; the Lee R. G. Snyder Memorial Fund; and a UC-Davis Faculty Research Grant.

\section{Literature Cited}

Agresti, A. 2002. Categorical data analysis. Second edition. John Wiley, Hoboken, New Jersey, USA.

Armitage, K. B. 1974. Male behaviour and territoriality in the yellow-bellied marmot. Journal of Zoology, London 172: 233-265.

Armitage, K. B. 1977. Social variety in the yellow-bellied marmot: a population-behavioural system. Animal Behaviour 25:585-593.
Armitage, K. B. 1984. Recruitment in yellow-bellied marmot populations. Pages 377-403 in J. O. Murie and G. R. Michener, editors. Biology of ground-dwelling squirrels. University of Nebraska Press, Lincoln, Nebraska, USA.

Armitage, K. B. 1987. Social dynamics of mammals: reproductive success, kinship, and individual fitness. Trends in Ecology and Evolution 2:279-284.

Armitage, K. B. 1989. The function of kin discrimination. Ethology Ecology and Evolution 1:111-121.

Armitage, K. B. 1991. Social and population dynamics of yellow-bellied marmots: results from long-term research. Annual Review of Ecology and Systematics 22:379-407.

Armitage, K. B. 1996. Resource sharing and kinship in yellowbellied marmots. Pages 129-134 in M. Le Berre, R. Ramousse, and L. Le Guelte, editors. Biodiversity in marmots. International Network on Marmots, Lyon, France.

Armitage, K. B. 2002. Social dynamics of yellow-bellied marmots: strategies for evolutionary success. Pages 9-16 in K. B. Armitage and V. Yu. Rumiantsev, editors. Holarctic marmots as a factor of biodiversity. ABF Publishing House, Moscow, Russia.

Armitage, K. B. 2003a. Marmots: Marmota monax and allies. Pages 188-210 in G. A. Feldhamer, B. C. Thompson, and J. A. Chapman, editors. Wild mammals of North America: biology, management, and conservation. Second edition. Johns Hopkins University Press, Baltimore, Maryland, USA.

Armitage, K. B. 2003b. Reproductive competition in female yellow-bellied marmots. Pages 133-142 in R. Ramousse, D. Allainé, and M. Le Berre, editors. Adaptive strategies and diversity in marmots. International Network on Marmots, Lyon, France.

Armitage, K. B. 2003c. Dynamics of immigration into yellowbellied marmot colonies. Oecologia Montana 12:21-24.

Armitage, K. B. 2004. Lifetime reproductive success of territorial male yellow-bellied marmots. Oecologia Montana 13:28-34.

Armitage, K. B., and D. W. Johns. 1982. Kinship, reproductive strategies and social dynamics of yellow-bellied marmots. Behavioral Ecology and Sociobiology 11:55-63.

Armitage, K. B., and O. A. Schwartz. 2000. Social enhancement of fitness in yellow-bellied marmots. Proceedings of the National Academy of Sciences USA 97:12149-12152.

Armitage, K. B., and D. H. Van Vuren. 2003. Individual differences and reproductive success in yellow-bellied marmots. Ethology Ecology and Evolution 15:207-233.

Bekoff, M. 1977. Mammalian dispersal and the ontogeny of individual behavioral phenotypes. American Naturalist 111: 715-732.

Blumstein, D. T., T. W. Wey, and K. Tang. 2009. A test of the social cohesion hypothesis: interactive female marmots remain at home. Proceedings of the Royal Society of London B 276:3007-3012.

Bollinger, E. K., S. J. Harper, and G. W. Barrett. 1993. Inbreeding avoidance increases dispersal movements of the meadow vole. Ecology 74:1153-1156.

Bowler, D. E., and T. G. Benton. 2005. Causes and consequences of animal dispersal strategies: relating individual behaviour to spatial dynamics. Biological Reviews 80 : 205-225.

Christian, J. J. 1970. Social subordination, population density, and mammalian evolution. Science 168:84-90.

Dobson, F. S. 1982. Competition for mates and predominant juvenile male dispersal in mammals. Animal Behaviour 30: $1183-1192$.

Dobson, F. S., and W. T. Jones. 1985. Multiple causes of dispersal. American Naturalist 126:855-858.

Ferreras, P., M. Delibes, F. Palomares, J. M. Fedriani, J. Calzada, and E. Revilla. 2004. Proximate and ultimate causes 
of dispersal in the Iberian lynx Lynx pardinus. Behavioral Ecology 15:31-40.

Frase, B. A., and K. B. Armitage. 1984. Foraging patterns of yellow-bellied marmots: role of kinship and individual variability. Behavioral Ecology and Sociobiology 16:1-10.

Gaines, M. S., and L. R. McClenaghan. 1980. Dispersal in small mammals. Annual Review of Ecology and Systematics 11:163-196.

Grant, P. R. 1978. Dispersal in relation to carrying capacity. Proceedings of the National Academy of Sciences USA 75: 2854-2858.

Greenwood, P. J. 1980. Mating systems, philopatry and dispersal in birds and mammals. Animal Behaviour 28: $1140-1162$.

Greenwood, P. J. 1983. Mating systems and the evolutionary consequences of dispersal. Pages 116-131 in S. R. Swingland and P. J. Greenwood, editors. The ecology of animal movement. Clarendon Press, Oxford, UK.

Gregory, M. J., and G. N. Cameron. 1988. Examination of socially induced dispersal in Sigmadon hispidus. Journal of Mammalogy 69:251-260.

Gundersen, G., and H. P. Andreassen. 1998. Causes and consequences of natal dispersal in root voles, Microtus oeconomus. Animal Behaviour 56:1355-1366.

Hanski, I. 2001. Population dynamic consequences of dispersal in local populations and in metapopulations. Pages 283-298 in J. Clobert, E. Danchin, A. A. Dhondt, and J. D. Nichols, editors. Dispersal. Oxford University Press, Oxford, UK.

Hanski, I., A. Peltonen, and L. Kaski. 1991. Natal dispersal and social dominance in the common shrew Sorex araneus. Oikos 62:48-58.

Holekamp, K. E. 1986. Proximal causes of dispersal in Belding's ground squirrels (Spermophilus beldingi). Ecological Monographs 56:365-391.

Holekamp, K. E., and P. W. Sherman. 1989. Why male ground squirrels disperse. American Scientist 77:232-239.

Howard, W. E. 1960. Innate and environmental dispersal in individual vertebrates. American Midland Naturalist 63:152161.

Ims, R. A. 1990. Determinants of natal dispersal and space use in grey-sided voles. Clethrionomys rufocanus: a combined field and laboratory experiment. Oikos 57:106-113.

Koopman, M. E., B. L. Cyper, and J. H. Scrivner. 2000. Dispersal patterns of San Joaquin kit foxes (Vulpes macrotis mutica). Journal of Mammalogy 81:213-222.

Lambin, X. 1994. Natal philopatry, competition for resources, and inbreeding avoidance in Townsend's voles (Microtus townsendii). Ecology 75:224-235.

Lambin, X., J. Aars, and S. B. Piertney. 2001. Dispersal, intraspecific competition, kin competition and kin facilitation: a review of the empirical evidence. Pages 110-122 in J. Clobert, E. Danchin, A. A. Dhondt, and J. D. Nichols, editors. Dispersal. Oxford University Press, New York, USA.

Matthysen, E. 2005. Density-dependent dispersal in birds and mammals. Ecography 28:403-416.

McGuire, B., L. L. Getz, J. E. Hoffmann, T. Pizzuto, and B. Frase. 1993. Natal dispersal and philopatry in prairie voles
(Microtus ochrogaster) in relation to population density, season, and natal social environment. Behavioral Ecology and Sociobiology 32:293-302.

Moore, J, and R. Ali. 1984. Are dispersal and inbreeding avoidance related? Animal Behaviour 32:94-112.

Murray, B. G., Jr. 1967. Dispersal in vertebrates. Ecology 48: 975-978.

Nunes, S., C.-D. T. Ha, P. J. Garrett, E.-M. Mueke, L. Smale, and K. E. Holekamp. 1998. Body fat and time of year interact to mediate dispersal behaviour in ground squirrels. Animal Behaviour 68:27-37.

Oli, M. K., and K. B. Armitage. 2008. Indirect fitness benefits do not compensate for the loss of direct fitness in yellowbellied marmots. Journal of Mammalogy 89:874-881.

Pusey, A., and M. Wolf. 1996. Inbreeding avoidance in animals. Trends in Ecology and Evolution 11:201-206.

Ronce, O. 2007. How does it feel to be like a rolling stone? Ten questions about dispersal evolution. Annual Review of Ecology, Evolution, and Systematics 38:231-235.

SAS Institute. 2009. SAS/STAT. Version 9.2. SAS Institute, Cary, North Carolina, USA.

Sharpe, L. L. 2005. Play does not enhance social cohesion in a cooperative mammal. Animal Behaviour 70:551-558.

Svendsen, G. E. 1974. Behavioral and environmental factors in the spatial distribution and population dynamics of a yellowbellied marmot population. Ecology 55:760-771.

Van Vuren, D. 1990. Dispersal of yellow-bellied marmots. Dissertation. University of Kansas, Lawrence, Kansas, USA.

Van Vuren, D., and K. B. Armitage. 1994a. Survival of dispersing and philopatric yellow-bellied marmots: what is the cost of dispersal? Oikos 69:179-181.

Van Vuren, D., and K. B. Armitage. 1994b. Reproductive success of colonial and noncolonial female yellow-bellied marmots (Marmota flaviventris). Journal of Mammalogy 75: 950-955.

Waser, P. M. 1985. Does competition drive dispersal? Ecology 66:1170-1175.

Waser, P. M., and W. T. Jones. 1983. Natal philopatry among solitary mammals. Quarterly Review of Biology 58:355-390.

Waser, P. M., and W. T. Jones. 1989. Heritability of dispersal in banner-tailed kangaroo rats, Dipodomys spectabilis. Animal Behaviour 37:987-991.

Wiggett, D. R., and D. A. Boag. 1992a. The resident fitness hypothesis and dispersal by yearling female Columbian ground squirrels. Canadian Journal of Zoology 70:19841994.

Wiggett, D. R., and D. A. Boag. 1992b. Natal dispersal in Columbian ground squirrels: is body mass the proximate stimulus? Canadian Journal of Zoology 70:649-653.

Wolff, J. O. 1992. Parents suppress reproduction and stimulate dispersal in opposite-sex juvenile white-footed mice. Nature 359:409-410.

Wolff, J. O. 1993. What is the role of adults in mammalian juvenile dispersal? Oikos 68:173-176.

Zedrosser, A., O.-G. Støen, S. Saibø, and J. E. Swenson. 2007. Should I stay or should I go? Natal dispersal in the brown bear. Animal Behaviour 74:369-376.

\section{APPENDIX A}

Number of occurrences for each of the categorical variables used in the analysis of dispersal of yellow-bellied marmots (Ecological Archives E092-018-A1).

\section{APPENDIX B}

Mean values of the continuous variables used in the analysis of dispersal of yellow-bellied marmots (Ecological Archives E092018-A2). 